\title{
Finding the T in fat
}

Recent research by three independent groups reveals an important link between $\mathrm{T}$ cells and metabolic disorders associated with obesity. Alterations in the composition of $\mathrm{T}$ cell populations that infiltrate adipose tissue are shown to influence the development of obesityassociated inflammation and insulin resistance. The studies raise the possibility of treating common metabolic disorders, such as type 2 diabetes, by targeting $\mathrm{T}$ cells.

Obesity is associated with chronic inflammation in adipose tissue, with inflammatory macrophages in particular accumulating in large numbers in visceral fat tissue. Now, all three groups show that $\mathrm{T}$ cells also infiltrate adipose tissue and contribute to obesity-associated metabolic complications in mice.

Nishimura et al. found that adipose tissue from obese mice (fed a high-fat diet) had more activated $\mathrm{CD}^{+}$effector $\mathrm{T}$ cells but fewer $\mathrm{CD} 4^{+}$ $\mathrm{T}$ cells than adipose tissue from lean mice (fed a normal diet), and that $\mathrm{CD}^{+} \mathrm{T}$ cell infiltration preceded the accumulation of macrophages. In vivo depletion of $\mathrm{CD}^{+} \mathrm{T}$ cells with CD8-specific antibody ameliorated insulin resistance and glucose intolerance induced by the high-fat diet. The therapeutic effect was associated with reduced infiltration of inflammatory macrophages and pro-inflammatory cytokine production in adipose tissue. Together with observations from in vitro experiments, these findings led the authors to propose that obese adipose tissue activates $\mathrm{CD}^{+} \mathrm{T}$ cells, which drive the recruitment of macrophages and their differentiation into an inflammatory rather than anti-inflammatory phenotype.

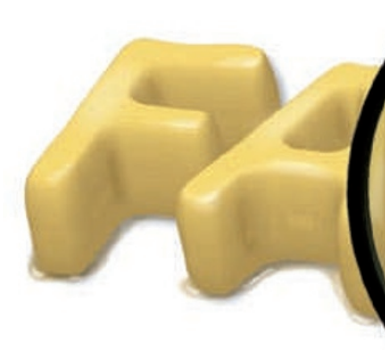

Winer et al. and Feuerer et al. focused on $\mathrm{CD}^{+} \mathrm{T}$ cells and showed that the balance between regulatory and effector $\mathrm{CD}^{+} \mathrm{T}$ cell subsets in adipose tissue was crucial in determining obesityassociated insulin resistance. Both groups found that in the visceral adipose tissue of obese mice interferon- $\gamma$-producing $\mathrm{T}$ helper 1 $\left(\mathrm{T}_{\mathrm{H}} 1\right)$ cells outnumbered $\mathrm{CD} 4^{+}$regulatory $\mathrm{T}\left(\mathrm{T}_{\mathrm{Reg}}\right)$ cells and $\mathrm{T}_{\mathrm{H}} 2$ cells; similar proportions of these $\mathrm{T}$ cell subsets were also seen in adipose tissue from obese humans. This suggested that a failure to keep pro-inflammatory $\mathrm{T}_{\mathrm{H}} 1$ cells in adipose tissues in check could precipitate insulin resistance. Interestingly, Winer et al. showed that the accumulation of $\mathrm{T}_{\mathrm{H}} 1$ cells in obese adipose tissue seemed to be antigen driven, because the infiltrating T cells showed a strong bias in T cell receptor (TCR) Va chain usage. Adoptive transfer of $\mathrm{CD}^{+}$(but not $\mathrm{CD} 8^{+}$) $\mathrm{T}$ cells into lymphocyte-deficient (recombination-activating gene $1^{-/-}$) mice fed a high-fat diet lowered serum levels of obesity-associated adipokines, normalized glucose tolerance and improved insulin sensitivity - an effect that was shown to depend on $\mathrm{T}_{\mathrm{H}} 2$ cells and not $\mathrm{T}_{\text {Reg }}$ cells. However, reconstitution of $\mathrm{T}_{\mathrm{Reg}}$ cells in adipose tissue was found to mediate long-term improvements in glucose and insulin homeostasis following transient $\mathrm{T}$ cell depletion in obese mice by treatment with a CD3-specific antibody.
Feuerer et al. extensively characterized the populations of $\mathrm{T}_{\mathrm{Reg}}$ cells in obese and lean fat, showing that fat-associated $\mathrm{T}_{\mathrm{Reg}}$ cells have a different gene expression profile from $\mathrm{T}_{\mathrm{Reg}}$ cells found at any other site, a specific TCR repertoire and evidence of antigen-driven selection. Experiments involving the depletion or induction of $\mathrm{T}_{\text {Reg }}$ cells in vivo showed an important role for these cells in guarding against excessive inflammation in adipose tissue and its downstream metabolic consequences.

So, these studies show that the microenvironment in obese adipose tissue can dysregulate $\mathrm{T}$ cell responses, tipping the balance towards inflammation and leading to obesity-associated metabolic complications.

Lucy Bird, Nature Reviews Immunology

ORIGINAL RESEARCH PAPERS Nishimura, S. et al. CD8 ${ }^{+}$effector T cells contribute to macrophage recruitment and adipose tissue inflammation in obesity. Nature Med. 15, 914-920 (2009) | Winer, S. et al. Normalization of obesity-associated insulin resistance through immunotherapy. Nature Med. 15, 921-929 (2009)| Feuerer, M. et al. Lean, but not obese, fat is enriched for a unique population of regulatory T cells that affect metabolic parameters. Nature Med. 15, 930-939 (2009) FURTHER READING Lumeng, C. N., Maillard, I. \& Saltiel, A. R. T-ing up inflammation in fat. Nature Med. 15, 846-847 (2009) 